\title{
Influence of Cultural Conditions on the Lipopolysaccharide Composition of Neisseria sicca
}

\author{
By I. J. McDONALD \\ Division of Biology, National Research Council of Canada, \\ Ottawa, Canada \\ AND G. A. ADAMS \\ Biochemistry Laboratory, National Research Council of Canada, \\ Ottawa, Canada
}

(Accepted for publication 14 December 1970)

\section{SUMMARY}

Growth rates of Neisseria sicca in batch cultures were controlled by changing aeration rates. Organisms cultured at high aeration rates grew more rapidly and had a greater proportion of lipopolysaccharide (LPS) than had organisms grown at low aeration rates. The LPS isolated from bacteria grown at a rapid rate had higher hexosamine and 3-deoxyoctulosonic acid (KDO) contents and higher galactosamine to glucosamine ratios than LPS from bacteria grown at a slower rate. These results indicated that environmental conditions affected the content and composition of the bacterial LPS. The LPS of organisms from highly aerated cultures had a larger percentage of unsaturated fatty acids than had that from organisms grown under conditions of low aeration, suggesting that oxygen-dependent desaturation of fatty acids had occurred.

\section{INTRODUCTION}

Considerable evidence has shown that the composition of wall polymers of several species of Gram-positive bacteria can be controlled by growth of the organisms in chemostats with different nutrients limiting growth (Tempest, Dicks \& Ellwood, 1968; Ellwood \& Tempest, 1969). Recently environmental conditions during growth have been shown to affect the composition of wall lipopolysaccharide (LPS) of Gramnegative Enterobacteriaceae. Quantitative differences in amounts of amino sugars and unknown reducing components were found in the LPS of Citrobacter freundii when batch cultures were grown in glucose or arabinose and at 5 or $45^{\circ}$ (Korczynski \& Wheat, 1970). When Aerobacter aerogenes was grown at a steady state in a chemostat, the ratio of the LPS components, heptose:3-deoxyoctulosonic acid (KDO), varied with changes in growth rate and with the nature of the growth limitation (Tempest \& Ellwood, 1969).

A previous paper (Adams, I97I) reported on the chemical composition of the LPS isolated from Neisseria sicca grown in a large batch (851.). In the present paper it is shown that both the yield and chemical composition of the LPS isolated from $N$. sicca varied when the growth rate of the organism was varied by changing the aeration rate. 


\section{METHODS}

Culture conditions. Stock cultures of Neisseria sicca (ATCC 9913) were frozen in liquid nitrogen. The organism was cultivated on trypticase soy (TS) broth (Baltimore Biological Laboratories). Organisms isolated from a single colony on TS agar were grown in 21 . of TS broth in a baffled 4 l. Erlenmeyer flask for $20 \mathrm{~h}$. at $25^{\circ}$ on a platform shaker operating at $100 \mathrm{rev} . / \mathrm{min}$. Bacteria were harvested aseptically and suspended in $100 \mathrm{ml}$. of sterile $25 \%$ glycerol. Samples $(2.5 \mathrm{ml}$.) were frozen in a dryice alcohol bath and stored at $-40^{\circ}$. These frozen organisms served as inocula for starter cultures in shake flasks $(0.5 \mathrm{ml}$. of thawed suspension/100 ml. of medium) and for experiments on the effect of different media on growth $(0.2 \mathrm{ml}$. of thawed suspension/100 ml.).

Four 1. baffled Erlenmeyer flasks containing I.25 l. amounts of TS broth $+0 \cdot \mathrm{I} \%$ yeast extract and $0.2 \%$ sodium succinate (TSYS) were inoculated with 10\% starter culture and were incubated with shaking (IOO rev./min.) at $25^{\circ}$. Growth was followed by determining the turbidity $(E)$ at $660 \mathrm{~nm}$. Before organisms were harvested by centrifugation, phenol was added to cultures to give a final concentration of $0.5 \%$ (or alternatively cultures were heated at $12 \mathrm{I}^{\circ}$ for $5 \mathrm{~min}$.).

Stirred jar fermentors (New Brunswick Scientific, Microferm, 7 l.) containing 51. amounts of TSYS broth were inoculated with $10 \%$ starter. Cultures were maintained at $25^{\circ}$ with controlled stirring $(800 \mathrm{rev} . / \mathrm{min}$.) and aeration rates (high $=1500 \mathrm{ml}$. air $/$ min.; low = $15 \mathrm{ml}$. air $/ \mathrm{min}$.). Growth was followed by determining turbidities $(E)$ at $660 \mathrm{~nm}$. At the completion of a run, phenol was added to give a final concentration of $0.5 \%$.

Organisms collected from stirred jars and shake flasks were harvested, washed twice with distilled water and freeze-dried.

Isolation of lipopolysaccharide (LPS). Lipopolysaccharides were extracted from the freeze-dried bacteria according to the phenol procedure of Westphal, Luderitz \& Bister (1952). The water-soluble phase was dialysed for $48 \mathrm{~h}$. and the crude LPS was recovered by freeze-drying. The freeze-dried material was suspended in water and an insoluble fraction was removed by centrifuging for $20 \mathrm{~min}$. at $44,000 \mathrm{~g}$. The soluble portion was then centrifuged for $8 \mathrm{~h}$. at 105,000 $\mathrm{g}$ and the LPS which sedimented as a clear gel was recovered as a white powder by freeze-drying.

Analytical methods. For sugar analyses, the LPS preparations were hydrolysed in I $-\mathrm{H}_{2} \mathrm{SO}_{4}$ for $\mathrm{I} 2 \mathrm{~h}$. at $100^{\circ}$ and neutralized with barium carbonate. Sugars were separated by paper chromatography using pyridine + ethyl acetate + water $(2: 5: 5)$ solvent as described previously (Adams, Kates, Shaw \& Yaguchi, I968). Neutral sugars were detected by alkaline silver nitrate (Trevelyan, Proctor \& Harrison, 1950) and by $p$-anisidine hydrochloride (Hough, Jones \& Wadman, 1950), amino sugars were detected by the Morgan-Elson reagent (Morgan \& Elson, 1934) and by ninhydrin ( $10 \%$ in acetone). Hexosamines were released from the LPS preparation by hydrolysing with $5 \mathrm{~N}-\mathrm{HCl}$ for $5 \mathrm{~h}$. Acid was removed by repeated distillation with water under reduced pressure at $35^{\circ}$. The hexosamine and sugar components were reduced and acetylated and the derivatives were analysed on a Pye Argon chromatograph with a column packing of $10 \%(w / w)$ neopentyl glycol sebacate polyester at $203^{\circ}$ (Adams et al. 1968). Quantitative estimation of the glucosamine:galactosamine ratio was made on the Technicon auto analyser using appropriate hexosamine 
standards; 3-deoxyoctulosonic acid (KDO) was determined colorimetrically (Weissbach \& Hurwitz, 1959). For analysis of fatty acids, LPS preparations were hydrolysed with methanolic hydrochloric acid (methanol, $3.5 \mathrm{ml}$; concentrated $\mathrm{HCl}, \mathrm{I} \cdot 5 \mathrm{ml}$.) essentially as described previously (Adams et al. I968). The fatty-acid methyl esters were extracted with petroleum ether + ethyl ether (I:I) and were analysed by gasliquid chromatography with a column packing of $10 \%$ butanediol succinate polyester (Adams et al. $\mathrm{I} 968$ ) at $\mathrm{I} 70^{\circ}$.

\section{RESULTS}

Preliminary experiments showed that both the rate and extent of growth of Neisseria sicca were increased considerably by the inclusion of $0 . \mathrm{I} \%$ yeast extract in TS broth. When various carbon sources were added together with yeast extract, the amount of growth of $N$. sicca was greater in the medium with $0.1 \%$ sodium succinate than in the other media tested (Table I). Carbohydrates such as glucose, sucrose or maltose were without effect possibly because of the high carbohydrate content of the basal medium. LPS from $N$. sicca grown in TS broth and in TS broth containing yeast extract and sodium succinate (TSYS) were compared; no compositional differences were detected. Therefore to ensure large crops, $N$. sicca was grown in TSYS broth.

Table I. Effect of yeast extract and various carbon sources on growth of Neisseria sicca in trypticase soy broth*

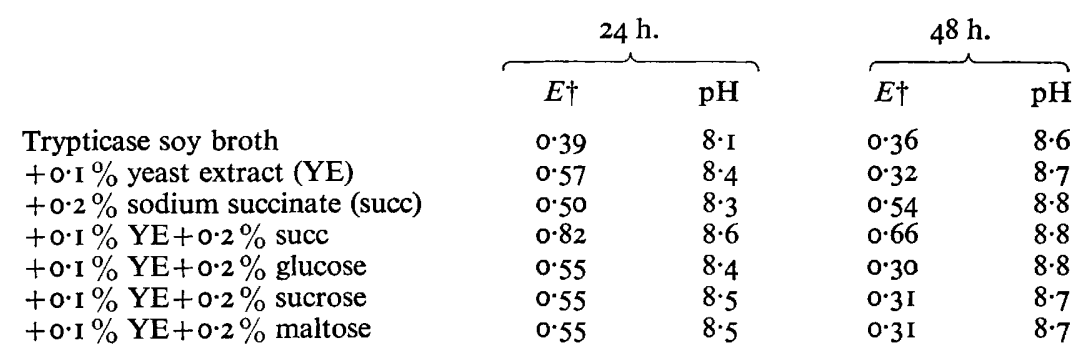

* Inoculum: $0.2 \mathrm{ml}$. thawed suspension of $N$. sicca $/ 100 \mathrm{ml}$. of medium; incubation at $25^{\circ} \mathrm{w} / \mathrm{shaking}$ (see text).

$\dagger E$ at $660 \mathrm{~nm}$.

Cultivation of Neisseria sicca under conditions of high or low aeration in stirredjar fermentors resulted in marked difference in growth rates (Fig. I). Doubling times of cultures grown at the high aeration rate were about $2 \mathrm{~h}$. (four trials), those of cultures grown at the low aeration rate were about $8 \mathrm{~h}$. (two trials). Some variation occurred between replicates probably because of slight differences in the flow rates of air, particularly at the low values.

The data presented (Tables 2, 3) are for the composition of LPS from cultures whose growth is shown in Fig. I. Other LPS samples, prepared from organisms taken at later times (e.g. 20 h.) from highly aerated cultures and at earlier times (e.g. I 2 h.) from slowly aerated cultures, gave similar results. The yield of Neisseria sicca LPS (mg./g. dry weight of bacteria) was considerably greater from highly aerated than from slowly aerated cultures (Table 2). In addition, the carbohydrate composition of the LPS varied with the growth conditions. LPS isolated from organisms grown at a rapid rate had a greater percentage of KDO and hexosamine and had a higher ratio 
of galactosamine to glucosamine than that isolated from organisms grown at a slower rate. The only neutral sugar detected in either sample was glucose.

When the organisms were grown in baffled flasks on a shaker, growth rates were about the same as in stirred-jar fermentors at the high aeration rate. The LPS of organisms from shake cultures had essentially the same glucosamine to galactosamine ratio and the same fatty-acid composition as LPS of organisms from highly aerated cultures (see Tables 2, 3). However, when shake-flask cultures were heated to kill the bacteria before they were harvested, the yield of LPS (mg./g. dry cells) was about $75 \%$ of the amount obtained from unheated orgainsms. LPS isolated from heated

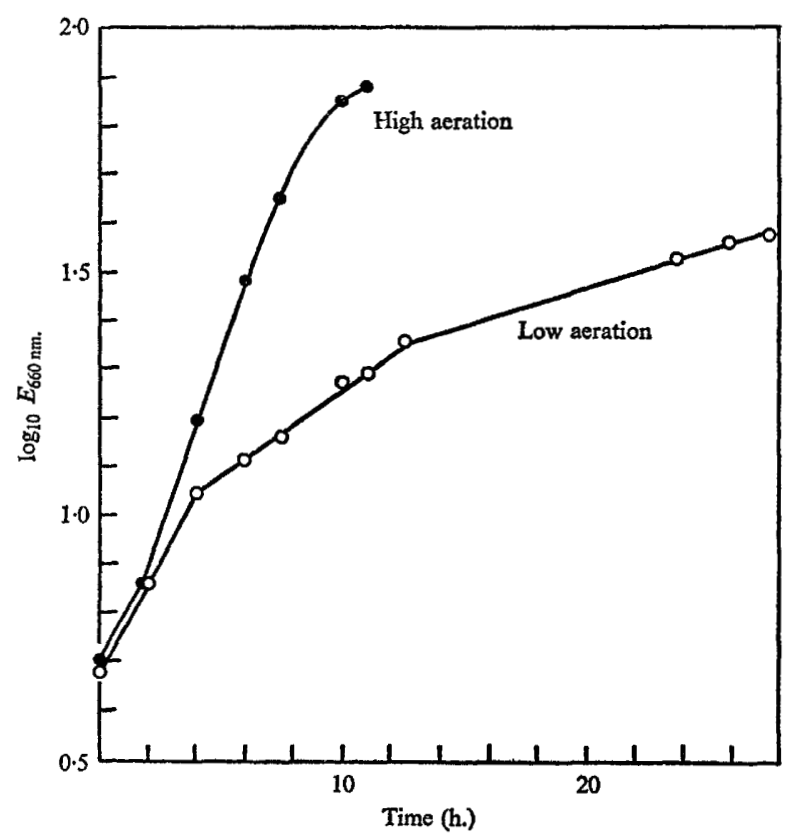

Fig. 1. Efiect of aeration on growth rate of Neisseria sicca at $25^{\circ}$. Cultures in 7.51 . stirredjar fermentors, stirring rate $800 \mathrm{rev} . / \mathrm{min}$. (high aeration $=1500 \mathrm{ml}$. air $/ \mathrm{min}$.; low aeration $=$ $15 \mathrm{ml}$. air $/ \mathrm{min}$.). Phenol ( $0.5 \%$ final concentration) added at II and $2 \mathrm{I} \cdot 75 \mathrm{~h}$. Medium $5 \mathrm{l}$. of trypticase soy broth (BBL) $+0.1 \%$ yeast extract and $0.2 \%$ sodium succinate.

Table 2. Hexosamine composition of lipopolysaccharides (LPS) isolated from Neisseria sicca grown under different conditions of aeration

\section{Component}

Dried organisms (g./1.)

LPS (mg./g. organisms)

Hexosamines (\% of LPS) $\dagger$

KDO (\% of LPS)

Glucosamine:galactosamine

Fatty acids (\% of LPS)

\begin{tabular}{|c|c|}
\hline \multicolumn{2}{|c|}{ Aeration rate* } \\
\hline High & Low \\
\hline 0.82 & 0.46 \\
\hline 68 & 33 \\
\hline $32 \cdot I$ & $9 \cdot 3$ \\
\hline $2 \cdot 87$ & $\mathrm{I} \cdot 25$ \\
\hline $\mathrm{I} \cdot 0: 8 \cdot 8$ & $1 \cdot 0: 1 \cdot 6$ \\
\hline $8 \cdot 8$ & $7 \cdot 7$ \\
\hline
\end{tabular}

$*$ High $=1500 \mathrm{ml}$. air $/ \mathrm{min} . ;$ low $=15 \mathrm{ml}$. air $/ \mathrm{min}$.

$\dagger$ Glucose was the only neutral sugar found. 
bacteria contained almost no galactosamine, indicating that a galactosamine-containing fragment was removed by heating the organisms under alkaline conditions. The above treatment $\left(\mathrm{I}^{2} \mathrm{I}^{\circ}\right.$ for $5 \mathrm{~min}$. at $\mathrm{pH} 8.4$ to 8.8$)$ may give a product similar to that obtained by alkaline extraction $\left(56^{\circ}\right.$ for $5 \mathrm{~h}$. at $0.25 \mathrm{~N}$ alkali) of Enterobacteriaceae (Luderitz, Staub \& Westphal, 1966).

Although the amount of fatty acids in LPS from organisms grown under high and low aeration conditions was about the same (Table 2), the fatty-acid composition of the LPS was affected by the conditions of growth (Table 3). LPS from highly aerated bacteria had most of the $\mathrm{C}_{1} 8$ acids present as the monounsaturated acid (CI8:I) whereas that from the slowly aerated organisms had about one-half of the $\mathrm{C}_{1} 8$ acids present as the saturated acid (Cr8:0). These results suggest that Neisseria sicca forms monounsaturated fatty acids by direct, oxygen-dependent desaturation of the corresponding saturated acids (Kates, 1966).

Table 3. Fatty acid composition of lipopolysaccharides of Neisseria sicca grown under different conditions of aeration*

\begin{tabular}{|c|c|c|c|}
\hline \multirow[b]{2}{*}{ Fatty acid $\dagger$} & \multirow{2}{*}{$\begin{array}{l}\text { Retention } \\
\text { relative to } \\
\text { myristate } \$\end{array}$} & \multicolumn{2}{|c|}{$\%$ of total fatty acids } \\
\hline & & High aeration & Low aeration \\
\hline Unident. & 0.42 & 0.1 & $0 . I$ \\
\hline $12: 0$ & 0.52 & $1 \cdot 9$ & 0.8 \\
\hline $12: 1$ & 0.58 & - & - \\
\hline 13:0:cyclopropane & 0.82 & 0.4 & 0.3 \\
\hline $14: 0$ & $1 \cdot 00$ & 0.3 & 0.3 \\
\hline Unident. & $\mathrm{I} \cdot 42$ & 0.4 & - \\
\hline Unident. & $1 \cdot 49$ & 0.4 & - \\
\hline 15:0:cyclopropane & 1.60 & 0.8 & $I \cdot O$ \\
\hline I6:0 & I.95 & $1 \cdot 9$ & $\mathrm{I} \cdot 8$ \\
\hline I6. I & $2 \cdot 19$ & 0.9 & 0.7 \\
\hline Unident. & $2 \cdot 31$ & 0.8 & - \\
\hline HO-I2:0 & $2 \cdot 75$ & $6 \cdot 0$ & 5.2 \\
\hline HO-I $2: 1$ & $2 \cdot 97$ & - & - \\
\hline Unident. & $3 \cdot 30$ & 0.7 & $3 \cdot I$ \\
\hline $18: 0$ & 3.86 & $2 \cdot 5$ & $12 \cdot I$ \\
\hline $18: I$ & $4 \cdot 26$ & $22 \cdot 3$ & $15 \cdot 4$ \\
\hline Unident. & $4 \cdot 7 \mathrm{I}$ & - & - \\
\hline $\mathrm{HO}-14: 0$ & $5 \cdot 50$ & $57 \cdot 3$ & $55 \cdot 2$ \\
\hline HO-I $4:$ I & 6.00 & - & - \\
\hline $20: 1$ & $8 \cdot 50$ & 0.5 & - \\
\hline Unident. & $9 \cdot 60$ & $\mathrm{I} \cdot 8$ & $3 \cdot 8$ \\
\hline
\end{tabular}

* See Table 2.

$\dagger$ The first number gives the chain length, the second gives the number of double bonds.

$\ddagger$ On $10 \%$ butanediol succinate polyester at $170^{\circ}$.

\section{DISCUSSION}

That the composition of most components of the bacterial cell can be influenced by changes in environmental conditions during growth has been observed frequently. For example, variations in amounts and composition of polysaccharides (Herbert, 1961), ribosomes (Sykes \& Tempest, 1965), lipids (Shaw \& Ingraham, 1965; Brown \& Rose, 1969) and cell walls (Young, 1965) have been found to occur, but it has only recently been stressed that a wide range of variations can occur in the composition of the bacterial walls (Ellwood, Turner, Hunter \& Moody, 1969), and of the LPS fractions, 
in response to changes in bacterial growth rate (Tempest \& Ellwood, 1969) and in the growth environment (Korczynski \& Wheat, 1970).

Changing the growth rate of Neisseria sicca by varying the aeration rate resulted in changes in the yield and in the carbohydrate composition of the isolated LPS. Because growth rates and aeration rates were not varied independently it is not possible to say whether the changes in LPS were due to altered growth rates, to altered aeration rates or to the combination of both. However, low growth rates of $N$. sicca, induced by oxygen limitation, resulted in the isolated LPS having a low KDO and low hexosamine content and a low ratio of galactosamine to glucosamine. Thus, $N$. sicca behaved in a manner very similar to that of Aerobacter aerogenes growing under carbon limitation in a chemostat (Tempest \& Ellwood, I969). If the LPS of $N$. sicca can be taken as a measure of wall substance then clearly the amount of wall changed in response to changes in the growth rate. The chemical composition of the LPS isolated from $N$. sicca changed also. Tempest \& Ellwood (1969) noted that cell wall KDO and heptose are both contained in a single wall polymer (the LPS layer) and that in $A$. aerogenes the ratio of KDO to heptose varied with the growth rate and with the nature of the growth limitation. It is not known whether changes in the composition of the LPS isolated from $N$. sicca were the result of changes in the ratio of two or more LPS fractions that responded independently to changes in the growth or to changes in the ratio of components of a single LPS molecule. It is clear, however, that the material isolated as LPS from $N$. sicca varied markedly in composition depending upon $(a)$ the environmental conditions during growth and $(b)$ the treatment given to cells (e.g. heat) prior to isolation of the LPS. It seems possible also that treatments used during the purification of LPS (e.g. selective acetylation; Adams, I97I) could markedly affect the composition of the final product.

Thus it is becoming abundantly clear that changes in the growth environment can lead to variations in composition of bacterial walls and of isolated LPS. Cognizance of these changes, therefore, is essential in any study of the composition of bacterial walls or LPS. That control of LPS composition by control of environment might be applied to the production of organisms with enhanced antigenicity has already been proposed (Tempest \& Ellwood, 1969). It seems possible also that control of changes in LPS composition might be useful in relating structure to antigenic response.

Fatty acid analyses were kindly provided through the courtesy of Dr M. Kates. We wish to thank Dr S. M. Martin for valuable discussions and Mr W. Rowsome and Mrs Doris Bilous for excellent technical assistance.

This paper was issued as N.R.C.C. no. II 733 .

\section{REFERENCES}

ADams, G. A. (1971). The chemical composition of a cell-wall lipopolysaccharide from Neisseria sicca. Canadian Journal of Biochemistry 49, 243-250.

Adams, G. A., Kates, M., Shaw, D. H. \& Yaguch, M. (I968). Studies on the chemical constitution of cell-wall lipopolysaccharides from Neisseria perfava. Canadian Journal of Biochemistry 46, II75-II84.

Brown, C. M. \& Rose, A. H. (1969). Fatty-acid composition of Candida utilis as affected by growth temperature and dissolved-oxygen tension. Journal of Bacteriology 99, 37I-378.

Ellwood, D. C., Turner, W. H., HunTER, J. R. \& MOody, G. R. G. (I969). Changes in the cell-wall composition of a strain of Bacillus subtilis grown in a chemostat. Biochemical Journal 113, 14 PI5P. 
Ellwood, D. C. \& Tempest, D. W. (1969). Control of teichoic acid and teichuronic acid biosynthesis in chemostat cultures of Bacillus subtilis var. niger. Biochemical Journal III, I-5.

HerberT, D. (1961). Microbial reaction to environment. Symposia of the Society for General Microbiology II, 39I-4I6.

Hough, L., JONES, J. K. N. \& WADMAN, W. H. (1950). Quantitative analysis of mixtures of sugars by the method of partition chromatography. V.Improved methods for the separation and detection of sugars and their methylated derivatives on the paper chromatogram. Journal of the Chemical Society, pp. 1702-1706.

Kates, M. (1966). Biosynthesis of lipids in micro-organisms. Annual Review of Microbiology 20, 13-44.

KORCZYNSKI, M. S. \& WhEAT, R. (1970). Environmental influence on lipopolysaccharide composition. Bacteriological Proceedings, p. 56.

Luderitz, O., STAUb, A. M.\&WeStPhal, O. (1966). Immunochemistry of O and Rantigens of Salmonella and related Enterobacteriaceae. Bacteriological Reviews 30, 192-255.

Morgan, W. T. J. \& Elson, L. A. (1934). A colorimetric method for the determination of $N$-acetylglucosamine and $\mathrm{N}$-acetylchondrosamine. Biochemical Journal 28, 988-995.

Shaw, M. \& Ingraham, J. L. (1965). Fatty acid composition of Escherichia coli as a possible controlling factor of the minimal growth temperature. Journal of Bacteriology 9o, 141-146.

SyKes, J. \& TEMPEST, D. W. (1965). The effect of magnesium and of carbon limitation on the macromolecular organization and metabolic activity of Pseudomonas sp., strain C-1B. Biochimica et biophysica acta 103, 93-108.

Tempest, D. W., Dicks, J. W. \& Ellwood, D. C. (1968). Influence of growth condition on the concentration of potassium in Bacillus subtilis var. niger and its possible relationship to cellular ribonucleic acid, teichoic acid and teichuronic acid. Biochemical Journal ro6, 237-243.

Tempest, D. W. \& Ellwood, D. C. (1969). The influence of growth conditions on the composition of some cell-wall components of Aerobacter aerogenes. Biotechnology and Bioengineering II, 775783.

Trevelyan, W. E., Procter, D. P. \& Harrison, J. S. (I950). Detection of sugars on paper chromatograms. Nature, London 166, 444-445.

WeISSBACH, A. \& HURWITZ, J. (1959). The formation of 2-keto-3-deoxyheptonic acid in extracts of Escherichia coli B. Journal of Biological Chemistry 234, 705-709.

WestPhal, O., LüDeritz, O. \& Bister, F. (I952). Über die Extraction von Bakterien mit Phenolwasser. Zeitschrift für Naturforschung 7 B, I48-155.

Young, F. E. (1965). Variation in the chemical composition of the cell walls of Bacillus subtilis during growth in different media. Nature, London 207, 104-105. 